\title{
SABERES TRADICIONAIS E INTERAÇÕES NA PRODUÇÃO DE ARTEFATOS CERÂMICOS NA COMUNIDADE QUILOMBOLA DE ITAMATATIUA - MA.
}

\author{
Cestari, Glauba Alves do Vale; Mestranda \\ PPGDg.Universidade Federal do Maranhão \\ glauba.cestari@terra.com.br \\ Guimarães, Márcio J. Soares; Mestrando \\ PPGDg.Universidade Federal do Maranhão \\ falecommg@gmail.com \\ Caracas, Luciana Bugarin; Ms. \\ Universidade Federal do Maranhão \\ 1.caracas@uol.com.br \\ Santos, Denilson Moreira; Dr. \\ Universidade Federal do Maranhão \\ denilson.santos@ufma.br
}

\begin{abstract}
Resumo: Este artigo trata do registro dos processos de produção artesanal em cerâmica adotados pela comunidade quilombola de Itamatatiua, localizada em Alcântara, no estado do Maranhão. Aborda as práticas tradicionais que caracterizam esse povoado e seus moradores que guardam o saber de modelar a argila a mais de três séculos. Apresenta, também, as mudanças introduzidas nas últimas décadas. Trata de tradição, inovação e valorização da cultura e de seus modos de produzir tijolos, telhas, potes, panelas, bonecas, placas decorativas, entre outros. Em suas especificidades e simbolismo, os artefatos são portadores da identidade local e representam importante fonte de renda. Considera, também, os diálogos entre técnicas e artefatos e as interações entre artesãs e outros atores, entre esses, o designer.
\end{abstract}

Palavras-chave: artesanato, tradicional, cerâmica, design, interações.

\section{INTRODUÇÃO}

\footnotetext{
"O artesanato revive e se recria quando encontra novas demandas e novas relações com os materiais, novas formas de produção e novas tipologias de produtos, que com a participação do design pode adequar-se às práticas sociais contemporâneas." ${ }^{1}$ (MORALES,2008.p.309)
}

\footnotetext{
${ }^{1}$ tradução do texto: Glauba Cestari.
} 
Este trabalho trata de produção artesanal tendo Itamatatiua, uma comunidade tradicional quilombola localizada no município de Alcântara ao norte do Estado do Maranhão, como estudo de caso. É uma investigação acerca da produção de artefatos em cerâmica iniciada na localidade há aproximadamente três séculos. Remete-nos a um passado ainda presente, onde artefatos e práticas passaram a diferenciar a localidade como um território de saberes e modos de produzir. Importa refletir quanto ao futuro dessa comunidade de artesãos onde tradição e atualidade se apresentam nos materiais, nos processos, nas idéias e no cotidiano de seu trabalho.

Produções artesanais nos direcionam à tradição, à identidade ${ }^{2} e$ à intervenção do design, sendo estes alguns dos temas recorrentes quando se pensa na construção da cultura ${ }^{3}$ material de um povo.

Fazer design é utilizar conhecimentos em busca de relações sociais mais democráticas e solidárias, voltadas não só ao crescimento capitalista, mas principalmente ao bem-estar comum. O papel do designer como facilitador de melhorias na cadeia produtiva ${ }^{4}$ do artesanato vem se desenvolvendo nos mais variados âmbitos. Em equipe, o designer contribui para o registro de atividades, o resgate e a valorização de atributos e especificidades, a promoção de mudanças relacionadas aos materiais e processos, à sustentabilidade, à estética e, entre outros, à comunicação.

A relevância deste trabalho está no registro do artesanato de Itamatatiua no qual destacamos aspectos do processo produtivo tradicional e, também, das mudanças realizadas nas últimas décadas.

\section{INTERVENÇÃO: artesanato e design}

O artesanato é fruto do acúmulo de saberes transmitidos por gerações. Os artesãos são herdeiros e detentores de um conhecimento tácito de inúmeras técnicas de extração e manipulação das mais diversas matérias-primas que sob sua expertise, são transformadas em artefatos cuja inspiração exprime os valores e a visão de mundo destes sujeitos, criando assim representações de sua identidade cultural.

No intuito de manter vivo este saber, instituições de fomento e de pesquisa têm se dedicado ao planejamento de ações que possibilitem a continuidade do artesanato tanto por seu valor cultural quanto por sua capacidade de ocupação e geração de renda. O design, por sua vez, em sua ampla atuação na pesquisa e no desenvolvimento de projetos de produtos, tem sido um instrumento de apoio neste processo de valorização do artesanato brasileiro.

No entanto, qualquer forma de intervenção, seja no intuito de realizar uma apresentação de soluções técnicas para o uso da matéria-prima, na renovação da oferta de produtos ou em sua logística de comercialização, implica em uma abordagem delicada: o risco da possibilidade de descaracterização dos produtos é contundente e deve ser seriamente avaliado.

\footnotetext{
${ }^{2}$ Identidade: "O termo está associado à idéia de que os artefatos têm a propriedade de refletir aspectos distintos de uma dada sociedade, como a sua história, sua cultura, sua ideologia, etc.”(COELHO. 2008. p.203)

${ }^{3}$ Tomando como referência COELHO (2008), o termo cultura está vinculado às manifestações de um povo, raça, grupo social ou civilização. A cultura de uma sociedade é formada pela produção de seus bens e valores, que através das coordenadas de tempo e espaço caracterizam as identidades de seus membros.

${ }^{4}$ por cadeia produtiva entende-se um conjunto de passos ou etapas técnicas consecutivas de produção integradas que envolvem desde a obtenção, transformação da matéria-prima até a distribuição do produto final. Essa cadeia integra materiais, processos (técnicas e tecnologias) e serviços (recursos humanos).
} 
Todavia, algumas experiências têm de certa forma gerado resultados significativos. Projetos desenvolvidos por pessoas que conhecem as realidades locais das regiões e que reconhecem os referenciais que distinguem os artefatos e sua importância enquanto representações culturais são responsáveis por uma aproximação benéfica, que tem como condição obrigatória a intervenção pautada na assimilação e manutenção dos símbolos e conceitos que conferem distintividade à forma de produção e ao produto.

\section{A COMUNIDADE DE ITAMATATIUA: quilombo e cerâmica}

A formação de comunidades remanescentes de quilombos no Estado do Maranhão tem sua origem no período de crise na produção e comércio do algodão e do açúcar, ocorrido entre os séculos XVIII e XIX (PAIXÃO, 2011), desencadeando um processo de abandono das terras por seus fazendeiros, o que favoreceu a ocupação e o uso destas terras pelos escravos. Ao contrário de outras áreas, Itamatatiua, não surgiu a partir de um grupo de fugitivos, mas daqueles que permaneceram nas terras abandonadas.

O povoado também conhecido como "Terra dos Pretos" ou "Terra de Santa Tereza" pertencia a Ordem das Carmelitas e possuía um espaço de produção artesanal de artefatos cerâmicos destinados à construção civil. A produção artesanal ao longo de três séculos tornou-se base de desenvolvimento do povoado (OOSTERBEEK, REIS, 2012). As peças de cerâmicas usadas como utensílios domésticos eram fabricadas em meio a telhas e tijolos, sendo importante seu uso nas casas dos moradores. Com o fim do empreendimento das Carmelitas a produção desses artefatos ganha uma nova dinâmica, como a separação da produção de utensílios domésticos da cerâmica voltada para a construção civil. Essa separação resultou também em uma divisão de gêneros de forma que tijolos e telhas são produzidos pelos homens, e potes, panelas, outros, passam a ser executados nos fundos das casas pelas mulheres (PEREIRA JUNIOR, 2011). Essa distinção permanece até a atualidade, visto que a produção de artefatos cerâmicos se divide entre o galpão de moldagem de tijolos e telhas, espaço instalado na casa de um dos moradores onde 2 a 3 homens exercem a prática e o Centro de Produção de Cerâmica, local onde cerca de 10 artesãs se reúnem para realizar a confecção de diversos artefatos artesanais, símbolos de sua cultura imaterial, enquanto ofício tradicional, que proporciona como resultado representações da rica cultura material elaborada por gerações. O centro constitui-se como espaço de produção, troca de experiências e de visitação, tornando-se atrativo turístico visitado por pessoas de diversas regiões do Brasil e de outros países.

Existem várias técnicas de fabricação de peças, porém a mais tradicional é a moldagem utilizando rolos ou serpentinas de argila. Produzem potes, vasos, panelas, travessas e outros artefatos. Já as artesãs mais jovens se encarregam da confecção de bonecas que representam as mulheres da região, seus costumes, hábitos e participações em manifestações folclóricas como o tambor de crioula e a dança do negro. As artesãs mais experientes dominam com precisão as técnicas de modelagem e de suas hábeis mãos nascem em instantes peças que deixam os expectadores perplexos com a destreza destas artesãs. Hoje a aplicação de novas técnicas, como por exemplo, a conformação de placas decorativas em cerâmica utilizando moldes de gesso, demostram que a tradição convive em equilíbrio com a inovação. 


\section{ABORDAGEM METODOLÓGICA.}

Este trabalho apresenta uma pesquisa de abordagem qualitativa descritiva, visto que a investigação ocorreu de forma direta e prolongada, in locum, com os atores envolvidos (LACATOS, MARCONI, 2011). Mediante contato mais próximo com os informantes (as artesãs) foi possível descrever as práticas locais. Os registros dessas foram realizados utilizando-se a técnica de observação assistemática participante. Para Marconi e Lacatos (2011), essa é uma técnica não estruturada, também denominada espontânea. É mais utilizada em estudos exploratórios e consiste em recolher e registrar fatos da realidade sem perguntas diretas ou planejadas. Para os autores, quando a observação é participante ocorre interação entre investigador e pesquisados ou colaboradores permitindo, desta forma, aproximação e maior confiança entre os indivíduos. Outros meios e técnicas também foram importantes à essa fase. Um diário de Campo (MINAYO,1993) para anotações, filmes e fotografias foram ferramentas essenciais. Optamos, também, por realizar entrevistas abertas sem planejamento prévio ou perguntas pré-estabelecidas. Estas aprofundaram o entendimento de aspectos particulares às práticas envolvendo: estruturas físicas, modo de produzir e suas etapas, mudanças e inovações ocorridas no processo.

A pesquisa bibliográfica foi essencial para fundamentar o trabalho quanto as formas de interações entre artesanato e design e ao objeto de estudo.

\section{PROCESSOS PRODUTIVOS DE ARTEFATOS CERÂMICOS EM ITAMATATIUA}

A produção de cerâmica de Itamatatiua caracteriza e identifica esse povoado e seus moradores que guardam o saber de produzir objetos de barro a cerca de três séculos. Em sua diversidade identificamos principalmente quatro processos, três tradicionais e um inserido recentemente, sendo eles respectivamente: a moldagem de tijolos e telhas em formas de madeira; a modelação com rolos na execução de potes e outros utensílios; a modelagem manual de bonecas e a modelação de placas decorativas sobre formas de gesso. Esses processos seguem etapas tradicionais: extração, beneficiamento, modelagem, secagem e queima.

Inicialmente, a extração da argila no barreiro, localizado na própria comunidade, é realizada pelas artesãs. Segundo relatos de Canuta ${ }^{5}$, a extração ocorre no verão e o destino do material é definido conforme a qualidade e uso na produção, pois em seu entendimento empírico, o barro da superfície é dispensado, a segunda camada é usada em telhas e tijolos e o mais profundo, considerado de maior plasticidade, é aplicado nos diversos artefatos do Centro de Produção de Cerâmica ${ }^{6}$.

0 transporte deste material ocorre por intermédio de cofo ${ }^{7}$ sobre a cabeça ou com ajuda de animal (jumento ou boi) ou ainda carro, dependendo da quantidade retirada. Em seguida é armazenado em dois locais: no espaço de produção de tijolos e telhas, organizado pelos homens; e no Centro de produção conduzida pelas mulheres, onde criam potes, vasos, bonecas, placas decorativas, etc.

Os processos após o transporte são realizados de forma independente nos locais citados.

\footnotetext{
${ }^{5}$ Artesã entrevistada durante pesquisa em Itamatatiua, no dia 29 de novembro de 2012.

${ }^{6}$ Segundo relatos em entrevista realizada com ceramista da comunidade o Centro de Produção de Cerâmica de Itamatatiua foi construído em 2004 por intermédio do governo do Estado.

${ }^{7}$ Cesto tipicamente utilizado na localidade e feito artesanalmente com fibras vegetais da região.
} 


\subsection{Sobre a prática de moldar tijolos e telhas}

A conformação de tijolos e telhas consiste em uma das práticas mais antigas. Além dos relatos que indicam a ocorrência dessa atividade desde a formação da comunidade, Registros históricos apontam para a produção de artefatos voltados à construção civil quando esse quilombo pertencia a Ordem das Irmãs Carmelitas (PEREIRA JÚNIOR, 2011)

Como já dito, na região esta é uma atividade masculina, no entanto, atualmente apenas dois a três indivíduos realizam a tarefa, garantindo a continuidade do ofício, que resiste ao tempo mesmo considerando o fato de várias residências da localidade serem atualmente construídas com materiais industrializados.

As etapas de produção acontecem em um barracão com estrutura de madeira coberto com palha de babaçu implantado na propriedade do artesão responsável. Neste a argila é depositada em um tanque escavado no próprio piso do local, sendo amassada de forma rudimentar com o artesão pressionando o material repetidamente com os pés e simultaneamente umedecendo-o com água. Esse procedimento tem como objetivo homogeneizar a massa, melhorando a plasticidade. Em seguida, esta matéria-prima é depositada próxima ao tanque sob sacos plásticos que devem manter umidade até serem modeladas em bancadas.

A conformação dos tijolos e telhas é feita com moldes de madeira. Para a telha é utilizado um molde côncavo com comprimento aproximado de cinquenta centímetros, chamado de "calha". Já o tijolo é modelado em um molde em formato de prisma retangular. Um instrumento chamado de garfo determina os furos dos tijolos após desmoldagem.

Ao final desses procedimentos, os produtos estão prontos para secagem que ocorre por cerca de quatro dias em tempo de sol ou até 10 dias durante inverno. A queima é realizada em forno à lenha feito de tijolos, no próprio espaço. Segundo Pereira Junior (2011), na queima, os tijolos ficam ao fundo, servindo de base para as telhas. A duração da cozedura é de aproximadamente 12 horas.

\subsection{A prática no Centro de Produção de Cerâmica: utilitários e decorativos}

As tradicionais técnicas aplicadas na produção de potes, panelas, bonecas e outros utilitários, acontecem paralelamente à conformação de placas decorativas, no Centro de Produção de Cerâmica de Itamatatiua (CPCI).
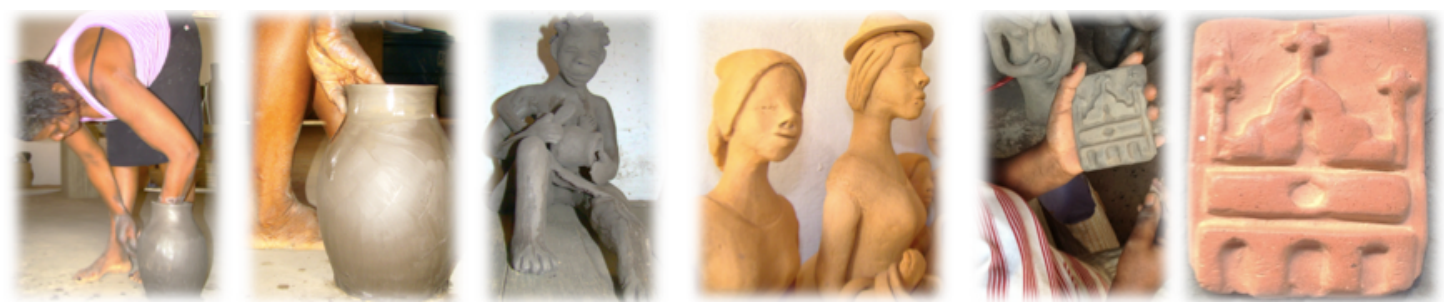

Figura1-Potes, bonecas e placas decorativas feitos no $\mathrm{CPCl}$. Fonte: elaborada pelo autor.

Esse espaço coletivo e essencialmente feminino, onde é possível fazer a estocagem, a preparação da argila para uso, a modelagem, a secagem, a cozedura e a venda. No processo, os diversos produtos têm várias etapas em comum. Apenas a modelagem é especifica à cada artefato.

O procedimento inicial consiste na estocagem da argila em um tanque de 
alvenaria com capacidade de armazenamento de $2,50 \mathrm{~m}^{3}$. Segundo relatos das artesãs ${ }^{8}$ o material extraído no verão, dependendo do volume de produção, é suficiente para uso durante todo o ano, inclusive no inverno ${ }^{9}$, época em que não ocorrem retiradas. Para conservarem condições de uso, a argila é umedecida diariamente com água e coberta com sacos plásticos.

No beneficiamento manual retiram-se pedras ou eventuais detritos e inicia-se o amassamento que é feito sobre a mesa de alvenaria, adicionando areia e água na preparação de porções de argila que são inseridas em uma maromba ${ }^{10}$. Os relatos das artesãs apontam para significativas melhorias no material após extrudado no equipamento. Anteriormente essa etapa era realizada apenas amassando a argila no piso com os pés ${ }^{11}$. Após extrusão, a massa é armazenada, para uso posterior, em baldes plásticos com tampa visando manter a umidade. Pode também ser imediatamente direcionada à produção. Nesse momento as artesãs colocam o material, sobre uma fina camada de areia, na bancada para evitar que a pasta ${ }^{12}$ adira na mesma e em seguida é novamente amassada e umedecida aos poucos, sendo submetida a repetidas batidas a fim de reduzir a formação de bolhas ${ }^{13}$ e torná-la macia. Percebe-se que as proporções são medidas pela prática e essa pasta é destinada à moldagem de todos os tipos de produtos do Centro.

A partir desta etapa, surgem especificidades na execução das tarefas, conforme tipo de produto. Os produtos utilitários, como os potes e vasos, tem acentuado valor simbólico, pois advém da técnica com rolos, a mais tradicional de todas.

\subsubsection{Sobre a prática de moldar potes e vasos}

Historicamente o pote é o utilitário de maior representatividade na produção local. Por séculos tinha função objetiva de transportar e armazenar água, no entanto, as inovações e mudanças na infraestrutura da comunidade, como a chegada da água encanada e dos modernos produtos de alumínio e plástico, o pote perde a utilidade prática chegando ao desuso. Segundo Noronha (2012), na década de 1990 o pote é resgatado como símbolo de identidade local através de projetos de intervenção que visavam a manutenção do artesanato local. Designers consultores do SEBRAE-MA compreenderam que este seria um autêntico produto do quilombo de Itamatatiua.

A modelagem dos utilitários é feita com a técnica de união de rolos, serpentinas ou tiras ${ }^{14}$, que são construídas manualmente e encaixadas num disco, mais precisamente num rebaixo junto ao seu contorno. Ali se coloca a primeira corda, seguida das demais por sobreposição. As cordas são unidas entre si por meio da pressão exercida pelas mãos. Nesta etapa, detalhes cuidadosos se apresentam com a experiência secular, por exemplo, as artesãs explicam que a ponta de cada corda é mais fina para que a união fique perfeita (sem volume no ponto de emenda entre

\footnotetext{
${ }^{8}$ Informação oral. Entrevista realizada no dia 29/11/2012.

${ }^{9} \mathrm{Na}$ região norte e nordeste do Brasil as estações são regidas por período de chuva (inverno) que se inicia no final do mês de dezembro até o mês de junho e período de seca (verão) que dura de julho a dezembro.

${ }^{10}$ A aquisição do equipamento, segundo Marcio Guimarães (designer pesquisador e consultor) ocorreu mediante projetos de aperfeiçoamento de arranjos físicos destinados a produção artesanal intermediados pelo SEBRAE-MA.

${ }^{11}$ Informação oral. Entrevista realizada no dia 29/11/2012.

${ }^{12}$ Compósito formado por argila, areia e água.

${ }^{13}$ Segundo Frigola (2002), as argilas são amassadas, seja de forma mecânica ou manual, para se eliminar as bolhas de ar e torná-las macias, plásticas e homogêneas.

${ }^{14}$ A técnica de união de tiras ou serpentinas, formas cilíndricas alongadas de argila, é utilizada também para fazer vasos, panelas, pratos, travessas. Segundo artesãs uma modelagem se diferencia da outra pela abertura que é determinada a medida em que se realiza os procedimentos. (observação de diário de campo em 29/11/2012)
} 
cordas). As dimensões dos produtos são variadas. Quando de grande porte, ao chegar à altura aproximada de $20 \mathrm{~cm}$ no decorrer da moldagem, é apoiado no piso e a artesã passa a girar em sua volta, sobrepondo as cordas e simultaneamente dando acabamento interno com as mãos que deslizam sobre a superfície ou com o auxílio da cuiupéua $^{15}$. É um procedimento peculiar que desperta interesse em todos os visitantes, pois o movimento em círculos é incomum, belo e exige habilidade e esforço. Por fim, as artesãs utilizam também lâminas de metal (facas ou estiletes) para dar acabamento final às bordas das peças.

Finalizada essa etapa aguarda-se a secagem e após esta, segue-se a queima, juntamente com todos os outros artefatos, entre eles as bonecas e peças decorativas.

\subsubsection{Sobre a prática de moldar bonecas}

Entre as peças decorativas, as bonecas detém grande importância, pois ilustram a história dessa comunidade expressando as festas, as danças típicas, a religiosidade, as cenas do cotidiano, os personagens reais da localidade. Além das feições, algumas adquirem um nome próprio, atribuído pela artesã que a confeccionou. Não se sabe ao certo quando ou quem iniciou essa prática, mas a arte de modelar as bonecas de cerâmica tem forte simbolismo, sendo admirada por muitos, inclusive por visitantes de outros países. Em certo momento houveram abordagens externas à comunidade, ocasionando modificações não necessariamente favoráveis, como uma oficina em que se instruiu a confecção de imagens de sereias e iemanjás ${ }^{16}$ que resultaram num forma de descaracterização dos produtos e sua identidade. Mais adiante, instituições de apoio ao artesanato, entre outros, resgataram a modelagem das bonecas tradicionais.

Seu processo de conformação inicia pelo compartimento da bola de argila já em dureza de couro ${ }^{17}$, em quatro partes iguais para bonecas menores (cerca de $25 \mathrm{~cm}$ de altura) e duas partes para bonecas maiores (entre 30 e $45 \mathrm{~cm}$ ). 0 procedimento inicia-se apenas com o uso das mãos. Cabeça, tronco e membros são uma peça única, para logo em seguida, com o auxílio de agulhas de crochê, serem realizados traços e vincos que definem o detalhamento das feições do rosto, mãos, pés ou sapatos (quando estes se apresentam, é comum que a peça tenha como base apenas o vestido). Orelhas, nariz, queixo e o afunilamento do pescoço são moldados à mão e para seus detalhes utilizam também palitos de madeira. Turbantes, cabelos ou brincos em formas de argola são feitos à parte e fixados com o uso da barbotina. Para cabelos crespos, recorre-se ao uso de um crivo. Constantemente a peça é levemente molhada para que se mantenha a plasticidade do barro e se evite o aparecimento de fissuras.

Após a conformação completa, a boneca fica em repouso por cerca de duas a três horas e em seguida, com o auxílio de um fio de nylon, é feito um corte transversal que separa a peça em duas metades: a da frente conserva os braços e a de detrás apenas uma seção da cabeça e tronco. Com o auxílio de uma colher ou espátula retirase parte da argila do interior da peça, deixando-a com uma espessura que permita a queima adequada e lhe confira leveza. Depois, as seções são unidas com barbotina.

\footnotetext{
${ }^{15}$ espátula feita com cabaça com dimensões de aproximadamente $10 \times 15 \mathrm{~cm}$. Essa ferramenta é empregada para deixar as superfícies dos potes, tanto no interior como exterior, mais lisas no decorrer da modelagem.

${ }^{16} \mathrm{O}$ reconhecido artesanato tradicional de Itamatatiua tem sido alvo de diversas instituições de fomento ao artesanato, que esporadicamente oferecem oficinas de criatividade, ministradas por designers ou artistas plásticos.

${ }^{17}$ Dureza ou consistência de couro diz respeito ao estado em que a argila está parcialmente endurecida, quando ainda conserva alguma umidade (FRIGOLA, 2002).
} 
Com a modelagem pronta, a boneca fica na secagem aguardando a cozedura. Após queima, as peças intactas permanecem na cor natural da cerâmica. Já as peças que porventura apresentam fissuras ou quebras são restauradas com o auxílio de gesso e cola, sendo pintadas em tinta látex com adição de pigmento líquido.

Ainda no que se refere aos decorativos as placas com a imagem da igreja local Santa Tereza D`Ávila - se diferenciam dos demais objetos por representarem uma técnica recentemente adotada pelas artesãs e por ser um artefato resultante das interações dos visitantes com a comunidade.

\subsubsection{Sobre a prática de moldar placas decorativas}

Ao longo do tempo foram inseridas algumas inovações na produção. Entre essas destacamos a conformação por molde de gesso. Com base em entrevista com as ceramistas identificamos que a origem desse artefato é atribuída às interações ocorridas com os turistas, que sugeriram a criação de novas peças. Segundo relatos, os turistas perguntavam, em visitas a loja do centro de produção durante a festa de Santa Tereza $^{18}$, se havia para vender uma igrejinh ${ }^{19}$ de cerâmica como souvenir. Surgiu assim a idéia de produzir algo que suprisse essa demanda, resultando em placas decorativas em cerâmica com a imagem da igreja de Santa Teresa D`Ávilla.

A inserção da técnica de conformação por molde de gesso ocorreu mediante oficina de capacitação oferecida pelo SEBRAE-MA e coordenada por uma artista maranhense (em 2012) a pedido das próprias artesãs ${ }^{20}$. Esse procedimento, que consiste em estampagem sobre molde por pressão manual é realizado de duas formas diferentes. A primeira consiste na formação de um disco de argila com espessura de aproximadamente 18 milímetros. Esse disco é colocado sobre o molde de gesso e pressionado no molde até preencher por completo toda a área interna. Após desmoldagem, de posse de uma lâmina de metal, cortam-se as rebarbas e com uma linha de nylon reduz-se a espessura para cerca de 15 milímetros. A segunda forma de moldagem se diferencia da primeira ao aplicar a argila em pequenas quantidades dentro do molde, pressionando o material contra as paredes deste. Com a área toda preenchida faz-se uma pequena bola de argila e pressionando-a contra a massa ainda dentro do molde, remove-se a placa decorativa. As etapas seguintes à desmoldagem são secagem e cozedura.

\subsubsection{Secagem dos artefatos}

A etapa da secagem é comum a todas as peças do Centro de Produção de Cerâmica. Nesta, os artefatos dispostos em prateleiras de madeira à sombra, tem variação no tempo de secagem. A artesã explica: "Depois de um dia, em tempo de sol, dá para levar ao forno. Em tempo de chuva, pode leva até uma semana" ${ }^{21}$. Quando secos são levados ao acabamento final com instrumentos específicos: lâminas de estilete ou faca para raspar rebarbas; lixa para eliminar defeitos na superfície; esponja

\footnotetext{
${ }^{18}$ Segundo Souza Filho e Andrade (2012), a festa de Santa Teresa D'Ávila, em Itamatatiua, ocorre anualmente desde o século XIX. No mês de outubro, durante três dias, recebe centenas de pessoas de São Luís, de povoados e municípios vizinhos.

${ }_{19}$ A igreja Santa Teresa de Ávila tem grande significado e muita representatividade na história do quilombo de Itamatatiua. A padroeira, considerada pelos quilombolas itamatatiuenses como protetora e dona das terras, foi trazida pela ordem das irmãs Carmelitas no Século XVIII. (PEREIRA, 2011)

${ }^{20}$ Informação oral obtida em entrevista com artesas realizada no dia 23/05/2013.

${ }^{21}$ Informação oral em entrevista realizada no dia 29/11/2012.
} 
levemente umedecida para reduzir imperfeições; polimento empedra ${ }^{22}$ (seixo rolado) e escova de cerdas de nylon para deixar a superfície lisa e com brilho acetinado.

\subsubsection{Queima dos artefatos}

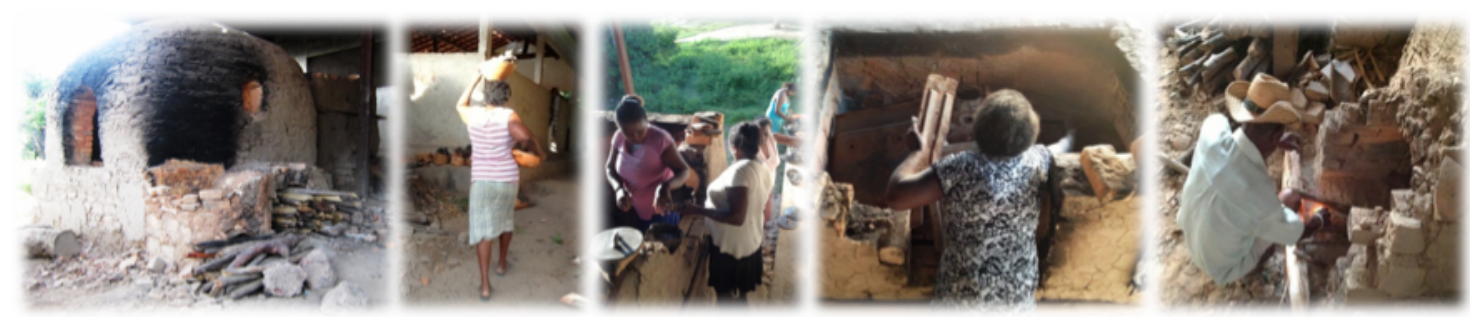

Figura 2 - Forno e procedimentos da queima. Fonte: elaborada pelo autor.

Finalmente ocorre a queima em forno a lenha, construído com tijolos fabricados na própria comunidade, que se subdivide em 3 (três) espaços com acessos específicos: uma boca com abertura frontal dá acesso ao maior espaço interno; a localizada à direita dá acesso ao menor espaço; e outra abertura superior, localizada aos fundos, leva ao espaço de médio porte. Cada compartimento possui sua própria câmara externa de abastecimento de lenha e desta é gerado o calor que circula pelo interior do forno atravessando as pilhas de artefatos cerâmicos.

O processo de queima ocorre como um ritual onde as peças são carregadas sobre a cabeça ou/e encaixadas na cintura e ao se aproximarem do forno as mulheres começam a passar os artefatos de mão à mão até chegar ao interior do forno onde, uma artesã aguarda e organiza as peças. Primeiro são colocadas peças quebradas em fornadas anteriores para forrar a base do forno ou são colocadas as peças grandes como potes, panelas, travessas e alguidares. Dentro das peças de maior porte ficam as pequenas como: canecas, colheres, as bonecas, as placas decorativas, entre outras. Ao preencher o forno as artesãs fazem o fechamento com chapas de metal, normalmente sucatas como peças de fogão.

Finalizada a tarefa descrita, exercida essencialmente pelas mulheres, inicia-se o trabalho do homem contratado para acompanhar a queima. O queimador ${ }^{23}$ providencia a lenha e acompanha as três etapas ${ }^{24}$ essenciais da queima: o esquente (aquecimento do forno), a cozedura e o esfriamento. O tempo necessário para estas é de no mínimo 4 (quatro) dias. Um dia para esquentar o forno, acrescentando lenha ao fogo aos poucos para aquecer gradativamente até chegar o ponto de cozedura ${ }^{25}$ que ocorre no segundo dia. O terceiro dia é destinado ao esfriamento, dentro do forno. Somente no quarto dia retiram-se as peças.

A retirada das peças é um momento de surpresas, pois conforme o posicionamento no interior do forno estas obtêm características diferenciadas quanto

\footnotetext{
${ }^{22}$ A pedra, comumente utilizada no polimento dos artefatos de Itamatatiua, não faz parte das etapas de acabamento das placas decorativas com a imagem da igreja de Santa Teresa D’Ávilla para evitar danos à imagem em alto relevo devido esforço exercido sobre a superfície.

${ }^{23}$ Denominação dada, na localidades, ao homem responsável por acompanhar as etapas de cozedura.

${ }^{24}$ As etapas de queima foram descritas com base em observação e entrevista com as artesas e com o Sr.Joty, responsável atualmente pelo procedimento de queima dos produtos do Centro de Produção. As entrevistas foram realizadas em duas etapas: em visita no dia 23/05/2013 e em visita de 17/06/2013 à 19/06/2013.

${ }^{25}$ Segundo dados obtidos com consultores do SEBRAE-MA o forno do Centro de Produção atinge o pico de $900^{0} \mathrm{C}$. A medição foi feita com pirômetro de cerâmica.(informação oral obtida em entrevista com a ceramista consultora do SEBRAE-MA em novembro de 2012).
} 
a coloração, ou seja, algumas peças ficam mais claras, outras mais escuras e outras com manchas pretas ${ }^{26}$. O fato não consiste em defeito, mas sim, em um efeito belo que agrada a uma parcela dos compradores, como as artesãs dizem "tem gente que gosta das queimadinhas. ${ }^{27 \prime \prime}$

\subsection{Escoamento dos artefatos de Itamatatiua}

Fechando a descrição da cadeia produtiva dos artefatos cerâmicos de Itamatatiua, observa-se diferenciações entre o escoamento do produto final dos espaços citados.

Segundo relatos dos artesãos ${ }^{28}$, a venda dos artefatos para construção civil ocorre por encomendas ou compra dos produtos disponíveis no local e os consumidores são principalmente moradores das comunidades próximas. Identificamos que em decorrência do projeto do governo "minha casa minha vida" muitas casas têm sido construídas com produtos industrializados em detrimento aos produtos feitos na localidade, fato que possivelmente trouxe impactos na comercialização desses.

No Centro de Produção de Cerâmica os artefatos são expostos na loja que faz parte da estrutura do local. O curioso na organização dos artefatos na loja é o fato de, mesmo sem nenhum tipo de sinalização nas peças, após misturá-las as artesãs sabem exatamente de quem é cada uma delas. Esse fato, provavelmente, deve-se às particularidades no modo de cada artesã produzir.

"Apesar de as mulheres trabalharem de forma coletiva e terem um centro de produção, a produção é individual. Na hora da venda as peças são separadas e a renda é revertida para as respectivas donas das peças, mesmo quando a associação detém um contrato de produção. As peças são colocadas no forno todas juntas sem separação, depois de pronta, cada mulher reconhece as suas, mesmo que sejam o mesmo tipo de peça, como potes e panelas". (PEREIRA JUNIOR, 2011. Pg. 41)

É importante destacar que a venda dos produtos que antes eram feitas nas próprias casas, na tradicional festa de Santa Tereza e também eram levadas através de barco ou animais à outras comunidades. Hoje, além de haver a possibilidade de escoamento dos produtos por variados meios de transporte (carros e ferry boat), a venda ocorre no Centro de Produção, em lojas existentes no município de Alcântara e em feiras de artesanato.

Segundo dados de Pereira Junior (2011), hoje as artesãs recebem encomendas de outros estados e até de outros países. No entanto observa-se que a encomenda parece não definir a questão produzir ou não produzir. A produção é diária e o ritmo se modifica conforme a existência de encomendas, ou seja, a encomenda não é obrigatoriamente o início do processo. Em Itamatatiua tudo começa com o desejo de produzir.

Um fluxograma apresenta a cadeia produtiva de Itamatatiua contemplando as etapas supracitadas( figura 3 ).

\footnotetext{
${ }^{26} \mathrm{O}$ forno do Centro de Produção é caracterizado como intermitente. Neste o material nao é cozido uniformemente, havendo até necessidade de desprezar algumas peças por falta ou excesso de queima (PETRUCCI, 1979).

${ }^{27}$ Narrativa de artesã em entrevista realizada em 23/05/2013.

${ }^{28}$ Iformação oral. Entrevista: Raquel Noronha, transcrição: Glauba Cestari. Data: 18/06/2013.
} 


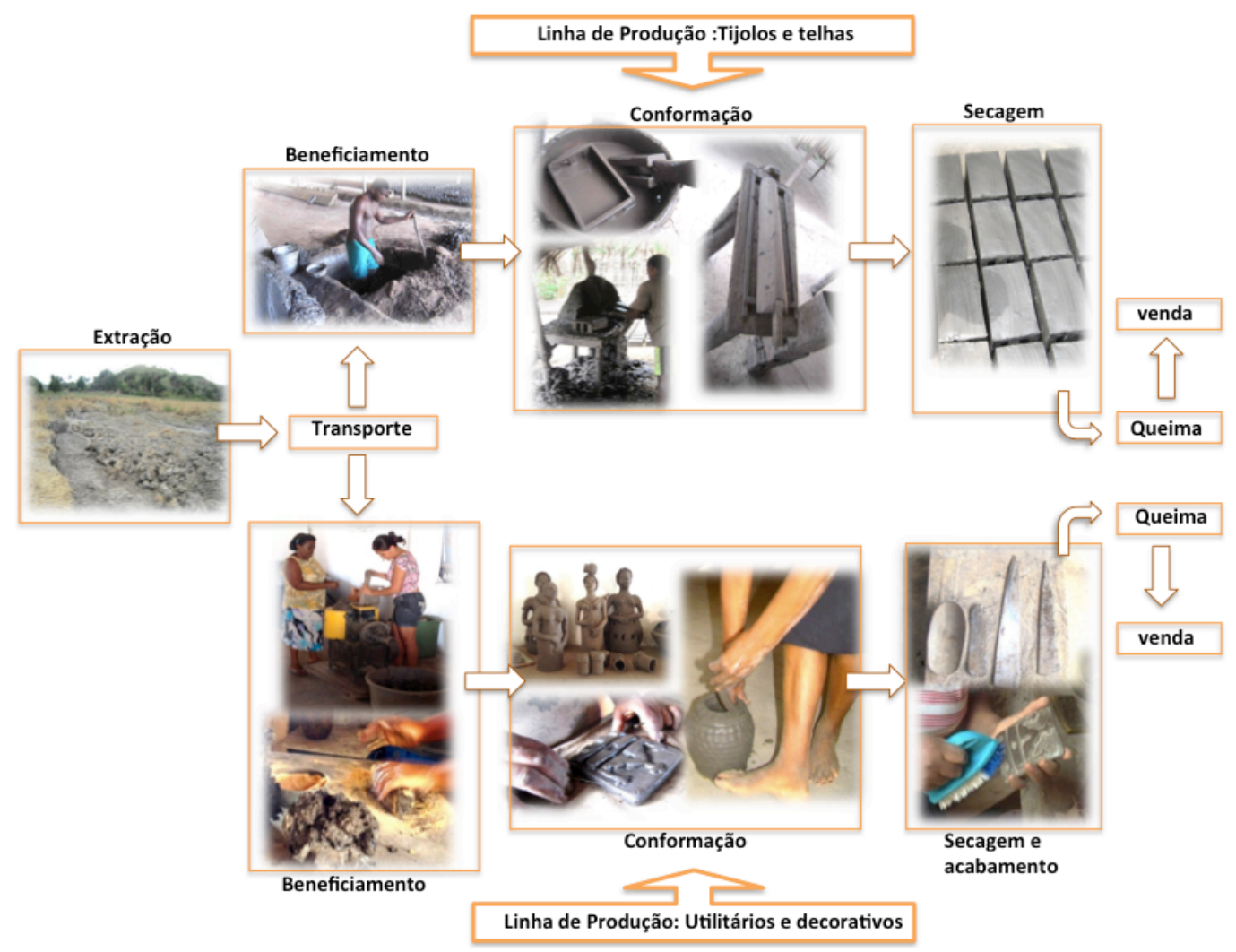

Figura 3 - Fluxograma. Fonte: elaborada pelo autor, com base na pesquisa realizada.

\section{CONSIDERAÇÕES FINAIS}

A produção de artefatos cerâmicos em Itamatatiua tem representatividade e veiculação comercial, expressa o imaginário de mulheres artesãs e torna-se importante como referência identitária do quilombo.

Ao longo do tempo, mudanças foram marcadas principalmente por dois momentos: o primeiro é caracterizado pelas transformações ocorridas na estrutura da produção com a saída das Irmãs Carmelitas; e um segundo momento configura-se na organização das mulheres de forma associativa resultando em inúmeras conquistas como a construção do Centro de Produção. Esse local fomentou interações com "o outro": artesãs, designers, pesquisadores, consultores, representantes de programas de incentivo ao artesanato, turistas, etc.

Estas interações foram em geral positivas, considerando as ações reconhecidas pelas artesãs ${ }^{29}$ como benéficas, gerando melhorias e favorecendo a manutenção das práticas artesanais. Entende-se que as interações entre o artesão, o designer e outros atores, considerando como premissa o entendimento da realidade local e sua cultura, podem ser valorosas tendo em vista que resultam em conquistas como melhor estrutura física para trabalhar, divulgar e transmitir seus conhecimentos.

Além disso, artefatos em vias de esquecimento ou desuso foram resgatados e valorizados no mercado atual. O contato com o turista, direta ou indiretamente, resultou em novos caminhos para o escoamento da produção assim como favoreceu o interesse por novas formas e técnicas.

Por fim, o registro dessa prática indica que mesmo diante das inovações e inevitáveis evoluções, o antigo e o novo coexistem como símbolos da história,

\footnotetext{
${ }^{29}$ Informação oral resultante de entrevistas in locum.
} 
identidade e resistência cultural dessa comunidade remanescente dos quilombos e ainda assim conseguem conquistar mercados.

Acredita-se que esse trabalho contribuirá para desenvolvimento de novas pesquisas que venham beneficiar essa comunidade e seus valores culturais imateriais e materiais, enquanto tradicional.

\section{REFERÊNCIAS}

BORGES, Adélia. Design + Artesanato: o caminho brasileiro. São Paulo: Editora Terceiro Nome, 2011.

COELHO, L. A. L. Coelho (org.). Conceitos-chave em Design. Rio de Janeiro: Ed. PUC Rio. Novas Idéias, 2008.

FRIGOLA, D.R.I. Cerâmica: técnicas decorativas. Lisboa: Editorial estampa, 2002.

LAKATOS, E. M.; MARCONI, M. A. Técnicas de pesquisa: planejamento e execução de pesquisa, elaboração, análise e interpretação de dados. 7.ed. São Paulo: Atlas, 2011.

MORALES, F. S. Diseño y artesanía. In:BONSIEPE, G.; FERNÁNDEZ, S. (coord.) História del diseño en América Latina y el Caribe: Industrialización y comunicación visual para la autonomía. São Paulo: Editora Blücher. 2008.p 308-322.

MINAYO, Maria Cecília de Souza. O Desafio do conhecimento. 2.ed. São Paulo: Hucitec-Abrasco, 1993.

OOSTERBEEK,L.;REIS,M.G.O. Terra de preto em terras da santa: Itamatatiua e as suas dinâmicas quilombolas. Cad. Pesq., São Luís, v.19, n.01, jan. / abr. 2012. Disponível em: <http://www.pppg.ufma.br/cadernosdepesquisa>. Acesso em: 26 de março de 2014.

PAIXAO, R. M. M. Reflexões sobre os quilombos e as mobilizações no Maranhão. In: MARTINS, C. C.; CANTANHÊDE FILHO, A.; GAIOSO, A. V.; ARAUJO, H. F. A. (org.). Insurreição de saberes: práticas de pesquisa em comunidades tradicionais. Interpretações do Maranhão. Manaus: Universidade do Estado do Amazonas - UEA, 2011. p 53-60.

PEREIRA JÚNIOR, Davi. Tradição e identidade: a feitura de louça no processo de construção de identidade da comunidade de Itamatatiua - Alcântara maranhão. In: MARTINS, C. C.; CANTANHÊDE FILHO, A.; GAIOSO, A. V.; ARAUJO, H. F. A. (org.). Insurreição de saberes: práticas de pesquisa em comunidades tradicionais. Interpretações do Maranhão. Manaus: Universidade do Estado do Amazonas - UEA, 2011. p 20-52.

NORONHA, R. G. Artesanato e consumo: comoditização da identidade étnica como estratégia territorial em Alcântara (MA). In: Reunião Brasileira de Antropologia, 2012, São Paulo. Anais da $28^{\circ}$ Reunião Brasileira de Antropologia. São Paulo: ABA, 2012.

SOUZA FILHO, B.; ANDRADE, M. P. Patrimônio Imaterial De Quilombolas - Limites Da Metodologia De Inventário De Referências Culturais. Horizontes Antropológicos, Porto Alegre, ano 18, n. 38, p. 75-99, jul./dez. 2012.

PICHLERA, R. F.; MELLOB, C. I. O. Design e a Valorização da Identidade Local. Design e Tecnologia 04. Pgdesign. UFRGS. Disponível em: http://www.pgdesign.ufrgs.br>. Acesso em: 21 de abril de 2014. 